\title{
A Multi-Criteria Evaluation Method of Product-Level Circularity Strategies
}

\author{
Yohannes A. Alamerew ${ }^{1, *(\mathbb{D}}$, Marianna Lena Kambanou ${ }^{2} \mathbb{D}$, Tomohiko Sakao ${ }^{2} \mathbb{D}$ and \\ Daniel Brissaud ${ }^{1}$ \\ 1 Univ. Grenoble Alpes, CNRS, G-SCOP, 38000 Grenoble, France; daniel.brissaud@grenoble-inp.fr \\ 2 Division of Environmental Technology and Management, Department of Management and Engineering, \\ Linköping University, 58183 Linköping, Sweden; marianna.kambanou@liu.se (M.L.K.); \\ tomohiko.sakao@liu.se (T.S.) \\ * Correspondence: yohannes.alamerew@grenoble-inp.fr; Tel.: +33-067-130-1936
}

Received: 10 April 2020; Accepted: 18 June 2020; Published: 23 June 2020

\begin{abstract}
The circular economy (CE) can drive sustainability. For companies to select and implement circularity strategies, they need to evaluate and compare the performance of these strategies both in terms of progress towards CE but also based on their feasibility and business outcomes. However, evaluation methods for circularity strategies at the product level are lacking. Therefore, this research proposes a multi-criteria evaluation method of circularity strategies at the product level which can be used by business decision-makers to evaluate and compare the initial business of the company, transformative and future circularity strategies. This multi-criteria evaluation method aims to assist business decision-makers to identify a preferred strategy by linking together a wide variety of criteria, i.e., environmental, economic, social, legislative, technical, and business, as well as by proposing relevant indicators that take into consideration, where possible, the life cycle perspective. It also allows for flexibility so that criteria, sub-criteria, and weighing factors can be altered by the business decision-makers to fit the needs of their specific case or product. Two illustrative examples based on case companies are presented to verify and illustrate the proposed method.
\end{abstract}

Keywords: circularity strategies; multi-criteria assessment; multi-criteria decision analysis; end-of-life strategies; circular economy; remanufacturing; resource efficiency; circularity indicators; sustainability; refurbish; repair

\section{Introduction}

In the last decade, the circular economy (CE) concept has become an issue of heightened interest for researchers, practitioners, policymakers, companies, and industries [1-3]. CE moves away from the conventional linear approach which utilizes a "make-use-dispose" economic model to one that is "regenerative by design" [4,5]. It aims to eradicate waste through careful design; reduce negative impacts; rebuild environmental, economic, and social capital; and maintain the value of products, components, and materials $[6,7]$. The value can be maintained through the implementation of various circularity strategies [8].

Currently, some companies are taking steps to implement circularity strategies and, therefore, more circular products and services are reaching the market $[9,10]$. However, widespread adoption of circularity strategies still has not taken place [11] and companies are struggling to implement and operationalize CE. This means that CE research is focusing on understanding the barriers and challenges that companies face (e.g., [11,12]) as well as developing decision-making support in the form of tools, metrics, and methods for companies to implement circularity strategies [13]. 
Research focused on the evaluation of circularity strategies for products and services compared to each other or to their business-as-usual counterparts or other products in the same product group which are just starting to take off [14]. More generally, there is a lack of evaluation methods of CE strategies of products and services at the micro level, i.e., product, company or single consumer-level [9,15-17] and there are few studies that have conducted and presented evaluations of such circularity strategies $[9,18,19]$. These kinds of evaluation methods can serve different purposes, e.g., strategy selection or identification of hotspots.

One specific area where business decision-makers need indicators or methods to help them evaluate circularity strategies is to select the best strategy when a product reaches the end-of-life (EoL) stage. There is a lack of such evaluation methods of product-level circularity strategies, as indicated by Sassanelli et al. [20] in a literature review on CE assessment methods and tools, and by Saidani et al. [10], who created a taxonomy of CE indicators including more than 55 sets of indicators. Elia et al. [9] supported this argument in the recent work on critical analysis of CE assessment and indicators at micro level.

The objective of this article is, therefore, to address the following research question (RQ):

RQ: How to evaluate circularity strategies for a product and/or service using a decision method to help a company select a suitable strategy at EoL stage?

Evaluating a circularity strategy cannot be done based on a single indicator or criterion, because apart from the contributing to waste reduction and negative impact mitigation, a strategy also needs to be feasible and financially viable and may require considerable investments [21,22] (see Section 2.2 for a more in-depth discussion). Therefore, the main research question is further broken down into two sub-questions:

1. What are the relevant criteria and sub-criteria/indicators to be used to evaluate circularity strategies?

2. How to evaluate circularity strategies using a decision-making method that incorporates the criteria and sub-criteria/indicators?

The overarching aim is to propose a decision-making method to evaluate circularity strategies of products and added services. The method evaluates potential alternative circularity strategies including (but not limited to) the initial or business-as-usual strategy of the company which could be traditional product sales or includes some form of product-level circular strategy, e.g., remanufacturing (reman), compared with various forms of more advanced or transformative strategies and future circularity strategies. Transformative strategies could be advanced remanufacturing, multiple or mixed reuse strategies and added service offerings (also known as product-service systems). The method aims to help business decision-makers to select the best feasible circularity strategy. It can be implemented at EoL phase by the company providing the initial product and third-party recovery/remanufacturing companies. Apart from introducing the method, this work gives two examples of its application and subsequent verification.

The organization of this article is as follows: Section 2 presents a literature review about CE, circularity strategies, decision-making factors, and CE assessment methods. Section 3 exposes the research methodology employed in this study to build the circularity strategies decision-making method. The results of this paper, i.e., the multi-criteria evaluation method of product-level circularity strategies, is presented in Section 4. Verification of the proposed method through cases is presented in Section 5. Section 6 discusses and summarizes the main findings of the study and points out future research opportunities. 


\section{Literature Review}

\subsection{The Circular Economy and Product Circularity Strategies}

The concept of circular economy has gained traction among scholars and practitioners, especially in Europe and China [23,24]. CE is an economic system in which the consumption of resources and emission of waste is minimized by keeping materials in the loop as long as possible [2,7]. Adopting CE could have considerable benefits in reducing waste volume and raw material inputs while supporting economic growth $[4,25]$. CE aims to retain the value of products, components, materials, and resources in the economy through the application of various circularity strategies $[8,26]$. Circularity strategies that extend product life and/or close resource loops include reuse, repair, refurbish, recondition, remanufacture, repurpose, cannibalization, and recycle [8,27]. Different circularity strategies are needed for different product characteristics, legislation, technology, and market dynamics [28]. The successful implementation of circularity strategies in businesses depends on combined leverage of various building blocks of $\mathrm{CE}$, amongst others, product and service design, business models, reverse supply chain, product and service use patterns, EoL recovery, and supporting policies [29-32]. Reverse logistics facilitate a number of circularity strategies such as reuse, refurbish, and remanufacturing and, therefore, are one of the building blocks of $\mathrm{CE}$, and an enabler for sustainable production and consumption [33,34]. The implementation of CE principles and strategies can facilitate meeting some of the United Nations' Sustainable Development Goals [10,35] by helping transform production and consumption behavior [36,37]. Figure 1 depicts a list of circularity strategies, which include:

- $\quad$ reuse/resell involves re-using a product if it meets sufficient quality levels [38-40];

- repair aims to recover a used product to "working order" by fixing/replacing specified faults using service and spare parts [41];

- refurbish involves returning products to a specific quality level, usually less than that of a new product [42];

- recondition involves returning the quality of a product to a satisfactory level (typically less than a virgin standard or new product) giving the resultant product a warranty less than that of a newly manufactured equivalent [41,43]. Reconditioned products have gone through more extensive testing and repair than refurbished products [42];

- remanufacture is a circularity strategy whereby EoL products are restored to the original equipment manufacturers' standard, and receive a warranty at least equal to a newly manufactured product [44-46];

- repurpose involves using post-used products for a different purpose and application compared to the original product $[32,47,48]$;

- cannibalization is an activity of recovering parts from returned products. Recovered parts are used in repair, refurbishing, reconditioning, and remanufacturing of other products [49]; and

- recycle aims to collect and process discarded materials that are then used for the production of new products $[40,50]$. 


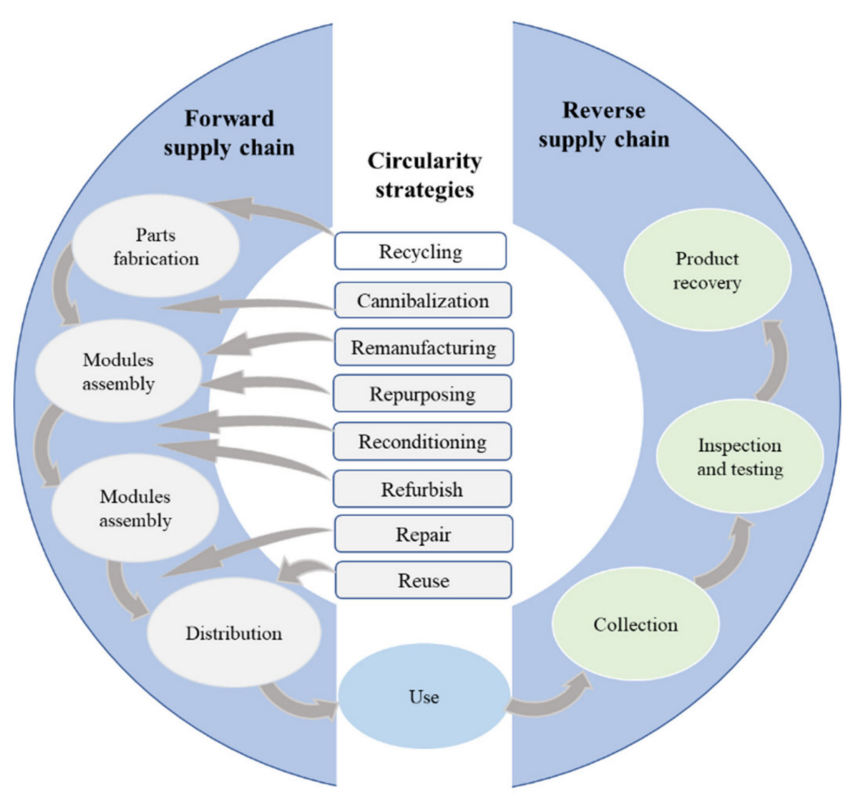

Figure 1. List of circularity strategies (adapted from [51]).

The circularity strategies terminology adopted in this article has been distinctly described in this section because overlaps exist and there is a lack of consensus about the specifics of each EoL strategy. EoL stage, in this work, refers to the point in time when the product reaches the end of its useful life with reference to the first user of the product. In addition, various literatures use different terminologies for the term "circularity strategies" such as circularity measures, circularity scenarios, circularity options, circularity alternatives, EoL options, recovery strategies, and resource efficiency strategies. In this paper, we use the term circularity strategies for better consistency throughout the manuscript. Moreover, circular strategies for bio-based products and technical products generally differ. The circularity strategies described above, and focused on here, are the ones that aim to close technical cycles. Selecting a suitable circularity strategy should take several factors into consideration [52,53]; this is further discussed in the following sections.

\subsection{Circularity Strategies' Evaluation Methods}

The CE paradigm can be analyzed at three levels of intervention: micro (product, company or single consumer level); meso (eco-industrial parks); and macro (cities, provinces, and regions) [54]. Although CE evaluation methods can be developed to meet the needs of various stakeholders, e.g., designers, industrial practitioners, policymakers, and consumers, the focus here, as discussed in the introduction, is on their use in decision-making at the micro level for businesses with a focus on evaluation of circularity strategies for EoL recovery.

Business decision-makers seeking to select circular strategies are not interested in simply measuring and understanding improved environmental performance or progress against the triple bottom line of sustainability, they need to understand the strategies' financial viability [21,55] and also their feasibility [22]. In fact, key practical challenges for businesses to implement circular economy strategies are customer demand and supply limitations, a lack of capital, regulatory uncertainty, and low or volatile material prices $[12,56]$. Technological challenges, such as material recovery techniques, are also listed as important but not as crucial as the market and regulatory challenges previously mentioned [11,57]. Moreover, all these challenges are amplified if there are internal company barriers, e.g., company culture and lack of awareness or trust or capabilities to implement CE (ibid.). Therefore, evaluation methods that aim to comprehensively evaluate circular strategies and support decision-makers have to both measure how well a product, service, or company performs with respect to the CE principles but must also take into consideration other important challenges for the businesses. 
Although the evaluation of circularity strategies is crucial for selecting the most appropriate one, it can also help identify hotspots and areas of improvement in order to overcome some of the challenges with moving towards CE [58,59]. For example, Kambanou and Sakao [55] demonstrated how Life Cycle Costing (LCC) can help compare business-as-usual to a circular scenario while also showing where large material and energy costs occur in the product's or service's lifetime so that decision-makers can focus on replacing these high costs with labor costs, e.g., maintenance activities in the circular scenario.

In recent years, there is a growing pool of academic studies that evaluate circularity strategies at a micro-level $[9,49,60]$. EoL evaluation methods can employ optimization, multi-criteria or empirical methods. Optimization evaluation methods use optimization problems to select the suitable circularity strategy from various alternatives. However, they are primarily focused on optimizing economic benefit $[61,62]$. Due to the complexity of mathematical models and their requirement of many input parameters, it is difficult for companies to use this method effectively and efficiently, while empirical methods are based on the knowledge and experience gained from analyzing successful cases rather than conventional rule-based methods [63]. Multi-criteria decision-making methods (MCDM) help decision-making in complex and inter-related decision tasks [64,65], and is further presented in the following section.

Table 1 presents a description of CE evaluation methods identified in this research. The Resource Conservative Manufacturing Project [66] developed a web-based tool, Circular Pathfinder (CP), to identify a suitable circularity strategy but focused on bio-cycles rather than techno cycles. However, this tool lacks scientific validation. Similarly, Alamerew and Brissaud [49] developed a product recovery decision-making tool to evaluate CE strategies on a strategic level. Lee, Lu and Song [67] presented an End-of-life Index (EOLI) method to evaluate product performance in relation to circularity strategies based on the calculation of total cost of each EoL process. The proposed index method assists designers to adopt design for EoL approach.

Table 1. Description of CE (circular economy) evaluation methods.

\begin{tabular}{ll}
\hline \multicolumn{1}{c}{ Method } & \multicolumn{1}{c}{ Description } \\
\hline Circular pathfinder (CP) & $\begin{array}{l}\text { A web-based tool to identify a suitable strategy based on a survey of 10 product-related } \\
\text { qualitative questions [66]. }\end{array}$ \\
\hline End-of-life index (EoLI) & $\begin{array}{l}\text { An EoL process cost-based index to evaluate circularity strategies including } \\
\text { remanufacturing, recycling etc. [67]. }\end{array}$ \\
\hline $\begin{array}{l}\text { Product recovery multi-criteria decision } \\
\text { tool (PR-MCDT) }\end{array}$ & $\begin{array}{l}\text { A CE evaluation tool that evaluates circularity strategies (remanufacturing, recycling, } \\
\text { repair, and reuse) at strategic level. The strategies are assessed according to relevant } \\
\text { economic, environmental and social indicators [49]. }\end{array}$ \\
\hline CE toolkit & $\begin{array}{l}\text { A web-based tool to assess product/service throughout the entire life cycle. The proposed } \\
\text { tool could be used by companies, distributers/retailers and consumers [68]. }\end{array}$ \\
\hline CE assessment dashboard & $\begin{array}{l}\text { A dashboard of new and established quantitative indicators is proposed for CE strategy } \\
\text { assessment in organizations [58]. }\end{array}$ \\
\hline Circularity potential indicator (CPI) & $\begin{array}{l}\text { A circularity performance indicator to measure the performance of products in the early } \\
\text { phases of a new or re-design product development [60]. }\end{array}$ \\
\hline Multi-criteria matrix & $\begin{array}{l}\text { A multi-criteria approach to assist decision-making for EoL management of electronic } \\
\text { products [69]. }\end{array}$ \\
\hline
\end{tabular}

\subsection{Multi-Criteria Evaluation Methods of Circularity Strategies}

A multi-criteria decision-making method (MCDM) is a tool used to select the best compromising strategy from a list of several potential alternatives by taking into consideration several criteria [70]. The method is usually used to solve complex problems by analyzing multiple criteria simultaneously based on both quantitative and qualitative information [71]. In MCDM, (i) the criteria, (ii) the indexes or sources of information used to measure the criteria, (iii) the weight and comparative value of the criteria can be tailored to the case (ibid.). Additionally, MCDM takes into account the preference of the user/decision-maker in the decision-making process [49]. In MCDM-based sustainability assessments, the choice and importance or weight of each criterion should take into consideration the values and 
context-specific knowledge of the decision-makers and be the outcome of stakeholder- inclusive discussions [22].

Because of MCDM's ability to provide structure to complex decisions, as well as the other characteristics mentioned above, it has been used when assessing sustainability solutions, e.g., [22,72]. Circular strategies, as discussed in Section 2.1, are a type of sustainability solution, and selecting them involves, as discussed in Section 2.2, various decision factors because there are multiple challenges and barriers to overcome. Moreover, multiple strategies could be relevant to compare. Therefore, MCDM can be a valuable method for evaluating circularity strategies.

With reference to Table 1, two methods for evaluating circularity strategies, the "multi-criteria matrix" and "PR-MCDT" (product recovery multi-criteria decision tool), have employed MCDM. The PR-MCDT helps to assess the feasibility of a recovery business or to test the performance of recovery strategies in order to improve a business [49]. In addition, the multi-matrix method [69] uses an MCDM to evaluate the EoL product and its components for recovery. This method uses evaluation criteria such as the residual value, environmental burden, weight, quantity, and ease of disassembly of each component. These two methods, however, have specific fields of application and therefore present a fairly restrictive set of criteria and indexes which might not fully capture the whole spectrum of relevant criteria for comprehensively evaluating circularity strategies. A more comprehensive list of criteria would need to address, first, the source challenges, as defined by Kirchherr et al. [11], as cultural, regulatory, market and technological as well as the potential benefits to the environment, society, and the economy.

The research on challenges shows that there are similarities between challenges, but they are also case-specific. Therefore, the MCDM should provide flexibility to decision-makers to choose the relevant criteria, sub-criteria and indicators. Furthermore, when drawing on knowledge of using MCDM for sustainability assessments, namely that setting criteria against each other or weighing them can require normative judgments [73], it can be surmised that as many relevant stakeholders as possible should be included in making the methodological choices of MCDM.

\section{Materials and Methods}

The point of departure for this research is a review of literature on the main themes related to the research question and sub-questions, namely, circularity strategies for a product and/or service, and evaluation methods of circularity strategies; identification and selection of decision-making criteria as well as sub-criteria and indicators. More than fifty relevant publications related to the subject area are reviewed. The research process for developing the evaluation method of circularity strategies for products and/or services includes (i) initial evaluation method selection, (ii) selection of criteria, sub-criteria and indicators, (iii) method development, and (iv) verification of the proposed method.

\subsection{Initial Method Selection}

A literature review was conducted to understand the state of the art on the evaluation of circularity strategies. As discussed in Section 2.2, circularity strategies' evaluation methods often employ optimization, multi-criteria, or empirical methods for decision-making. Based on the review of literature concerning the challenges and complexity faced by companies implementing circularity strategies (Section 2.2), the advantages and disadvantages of using each method for decision-making are analyzed. In this paper, a MCDM approach is used to develop a circularity strategies' evaluation method. The reasons for choosing MCDM are: (i) that a wide range of criteria can be included, (ii) both qualitative and quantitative data can be incorporated, and (iii) flexibility and tailoring to the case requirements is allowed (see Section 2.3 for an in-depth review).

\subsection{Selection of Decision Criteria, Sub-Criteria and Indicators}

Based upon a comprehensive literature review of more than 50 relevant publications and feedback from five experts in the subject domain, decision-making criteria, sub-criteria and indicators are 
identified. Firstly, an exhaustive list of criteria was made. Then the decision-making factors were sorted into various categories (i.e., business, technical, economic, environmental, legislative and societal) by the authors as seen in Table 2. Afterwards, the list was updated and verified based on expertise feedback from the industry and academia. Detailed results of this research can be accessed from Alamerew and Brissaud (2018) [49]. This list was revisited in preparation of this article and checked against literature, e.g., challenges and barriers to circular strategy adoption, published in intervening years, i.e., 2018-2020. In accordance with MCDM methodology, this list is recommended but not required since decision-makers can choose the most relevant criteria, sub-criteria and indicators for their case.

Table 2. List of decision criteria and sub-criteria [49].

\begin{tabular}{ll}
\hline \multicolumn{1}{c}{ Criteria } & \multicolumn{1}{c}{ Sub-Criteria/Indicator } \\
\hline Environmental & Life Cycle Assessment (LCA), EoL impact indicator (EOLI), Human health (HH), Ecosystem quality (EQ), Resources (R), \\
Economic & Life Cycle Costing (LCC), disassembly cost, net recoverable value, logistics cost, EoL treatment cost, \\
Social & Job creation opportunity, exposure of employees to hazardous materials, level of customer satisfaction, \\
Legislative & Effect of legislative pressure, compliance with new and existing legislation, \\
Technical & Technical state, availability of recovery facilities, separability of materials, advancement in technology, presence/removability of \\
Business & hazardous content, \\
\hline
\end{tabular}

\subsection{Method Development}

Due to the complexity of circular systems, an integrated approach is required to incorporate all the decision-making criteria and to take into consideration both quantitative and qualitative factors. Based on the result of a comprehensive literature review, evaluation of circularity strategies can be formulated as an MCDM problem. The multi-criteria evaluation method of circularity strategies involves (i) description of the product under consideration, (ii) finding potential circularity strategies, (iii) identifying evaluation criterion and decision-making factors, (iv) evaluation of circularity strategies, and (v) analysis and ranking of circularity alternatives.

In this study, MCDM is used to build the proposed method. The proposed method is first developed based on simple multi-attribute rating technique (SMART) [74-76]. SMART is a multi-criteria decision-making method that can comprehensively account both qualitative and quantitative criteria. Afterward, the authors reduce the complexity in order to develop a practical method that can be effectively applied to real case studies. All authors contributed to the development of the method by iteratively commenting on the method during the development period.

\subsection{Verification of the Method}

To verify the application of the proposed circularity strategies' evaluation method, two illustrative examples are presented based on two case studies. Secondary data from two Swedish companies, so-called Company A and Company B, is used to exemplify the application of the method. Company $A$ is involved in waste management whereas Company B is a storage furniture supplier. Descriptions of the case companies are presented in Section 6.

\section{Multi-Criteria Evaluation Method of Product-Level Circularity Strategies Description}

In this section, the main contribution of the research is presented. An MCDM is proposed to evaluate alternative circularity strategies for products in a specific company at the EoL stage. The proposed MCDM consists of five main steps: (I) description of the product and/or service under consideration, (II) identification of potential circularity strategies, (III) identification of evaluation criteria, sub-criteria and indicators, (IV) evaluation of circularity strategies, and (V) analysis and ranking of alternative circularity strategies. The focus of this method is on steps III and IV. The graphical representation of the method is shown in Figure 2. In this section, each step of the evaluation method is described in detail. 


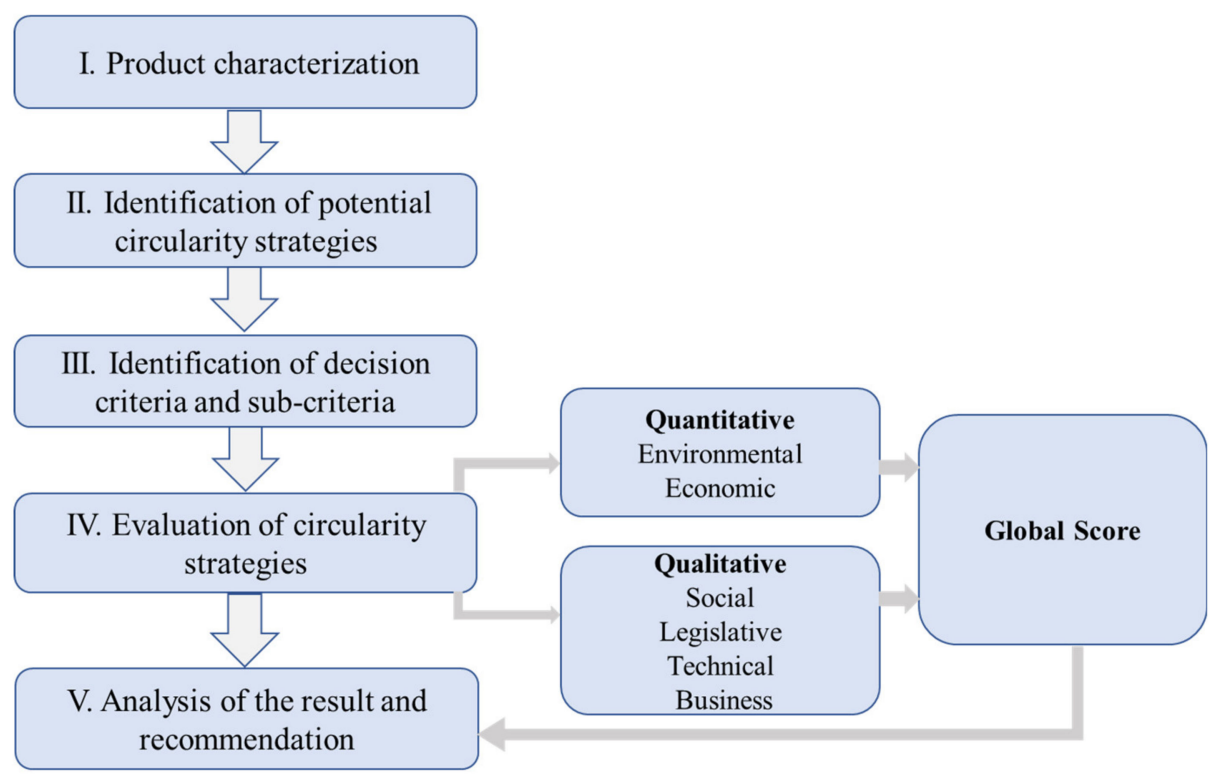

Figure 2. Depiction of the main steps of the proposed method.

\subsection{Product Characterization}

This first step of the method aims to identify the main characteristics of the product and/or service under consideration. This information will help to identify decision-making criteria and potential circularity strategies that are relevant to the product at hand, in the next steps of the methodology [77]. A potential circularity strategy is a possible candidate for evaluation and comparison during the decision-making process [78]. A description of the product is decisive for a company to be able to efficiently choose potential circularity strategies for a typical product. Description of the product covers relevant information regarding its characteristics, e.g., type of components and materials as well as functional use by the consumer. The main output of this step is to identify characteristics that influence the selection of circularity strategies.

\subsection{Identification of Circularity Strategies}

Based on the outputs of step 1, i.e., description of characteristics of the product, in this step, potential circularity strategies are identified. First, the current business strategy of the company (business-as-usual or traditional business strategy) is identified from a set of circularity strategies defined in Section 2.1. Then potential transformative strategies are selected based on the characteristics of the product outlined in Section 4.1 and a set of circularity strategies defined in Section 2.1. The transformative strategy can be identified from the current business model of the company in case if the company is implementing circular strategies. Transformative circularity strategies may include strategies such as advanced remanufacturing, multiple/mixed reuse strategies and product service offerings. Afterwards, a possible future strategy is identified that may have considerable business potential for the company in the near future. The main output of this step is a list of potential circularity strategies.

Depending on the specifics of the case, e.g., company size and complexity of the supply chain, it can be relevant to include a variety of stakeholders in this step and, as well, as employ tools that support innovation for a circular economy. Bocken et al. (2019) [79] have reviewed such available tools and new ones are being developed, e.g., Bloosma et al. (2020) [59].

\subsection{Identification of Decision Criteria, Sub-Criteria and Indicators}

There are various factors that influence the choice of a circularity strategy of products at EoL stage $[12,14,61]$ (see Section 2.2). Based on a systematic literature review, Alamerew and Brissaud 
(2018) [49], developed a list of CE evaluation criteria as well as sub-criteria, and evaluation indicators that are presented in Table 2.

The list consists of both quantitative and qualitative criteria. These criteria cover, as discussed in Sections 2.2 and 2.3, the circular strategies' potential contributions to CE, i.e., environmental, economic, and social, as well as their feasibility, i.e., legislative, technical, and business. The latter three criteria also coincide with three of the four major challenges faced by companies when implementing circular strategies, which were identified more recently by Kirchherr et al. (2018) [11] as cultural, regulatory, market, and technological. Therefore, the criteria in Table 2 are the recommended criteria for evaluating circularity strategies.

Alamerew and Brissaud (2018) [49] also suggest sub-criteria and indicators that can be used when setting values to the criteria (Table 2). Not all the sub-criteria need to be used, e.g., only Life Cycle Assessment (LCA) could be used to evaluate the environmental criterion. Moreover, the list is not exhaustive, as new indicators targeting the circular economy are constantly being introduced. For example, Pauliuk (2018) [58] makes a strong case for using Material Flows Analysis (MFA) as an indicator of circularity.

Concerning the three criteria for assessing contributions towards a circular economy, i.e., environmental, economic, and social, there is a strong recommendation to use life cycle approaches because circularity strategies that influence one life cycle stage can shift burdens to other life cycle stages $[77,80]$. Therefore, Life Cycle Assessment (LCA) and LCC are recommended as the indicators for evaluating environmental and economic criteria respectively and care should be made when making methodological choices so that they can be used in parallel [81]. Since Social Life Cycle Assessment (SLCA) is not robust and widely used [82], other types of qualitative indicators are recommended as sub-criteria or indicators for the criterion "social".

Concerning the three feasibility criteria, i.e., legislative, technical, and business, there is a strong recommendation that decision-makers use qualitative indicators. For example, a scoring table including three: 3-High; 2-Average; 1-Low; or five scales: 5-Very high; 4-High; 3-Average; 2-Low; 1-Very Low can be used. Additionally, more than one type of indicator can be used so that multiple areas within a criterion are covered, e.g., volatility of the price of recovered materials and expected demand.

It must be clarified that criteria, sub-criteria, and indicators can be changed depending on the specifics of the case, such as the complexity of the supply chain, the decision-makers' normative values, the availability of data, and the type of the product under consideration. For example, some companies might add a criterion about "company culture". Learnings from the research on challenges companies face when implementing circularity strategies, e.g., Kirchherr et al. (2018) [11], Mont et al. (2017) [56], Rizos et al. (2016) [12] indicate that challenges are case-specific although there are some similarities. Therefore, it is especially important that the sub-criteria and indicators for legislative, technical, and business criteria are chosen carefully by decision-makers to suit the context.

Finally, as proposed by Lindfors et al. (2019), every effort should be made so that criteria, sub-criteria, and indicators are comprehensive but do not overlap, and that relevant stakeholders are included in the process of identifying them [22].

\subsection{Evaluation of Circularity Strategies}

After identifying the list of circularity strategies and evaluation criteria, sub-criteria, and indicators, the next phase of the method is to evaluate each alternative circularity strategy against the decision criteria. The main output of this step is an assessment value for each circularity strategy. The graphical representation of the main steps of the proposed evaluation method is shown below in Figure 2 .

A typical problem consists of a set of available circularity strategies $A_{i}(i=1,2, \ldots, n)$. Circularity strategies are evaluated against a set of criteria $C_{j}(j=1,2, \ldots, m)$. Each criteria $C_{j}$ may be broken down into $P_{j}$ sub-criteria (decision factors) or indicators, $C_{j k}\left(K=1,2, \ldots, P_{j}\right)$. The decision-maker is 
expected to evaluate circularity strategies with respect to each decision criteria denoted as $X_{i j}(i=1,2$, $\ldots, n ; j=1,2, \ldots, m)$.

The general model applied for the proposed method is:

$$
\mathrm{M}(\mathrm{Ai})=\Sigma \mathrm{W}_{\mathrm{j}} \mathrm{X}_{\mathrm{i}(\mathrm{j})}, \mathrm{j}=1,2, \ldots \mathrm{m}, \mathrm{i}=1,2, \ldots, \mathrm{n},
$$

where:

$W_{j}$ is the weighted value of $j$ of $m$ criteria

$X_{i(j)}$ is the value of $i$ of criterion $j$

$M_{(A i)}$ is total evaluation result for each strategy.

The weighting value $\left(\mathrm{W}_{\mathrm{j}}\right)$ is assigned based on the relative importance of each criterion/sub-criterion for the evaluation decision. It depends on the type of product, the type of industry, and the perception of the decision-maker. In this step, the decision-maker assigns the value based on experience with the business-as-usual product and strategy. Often, many decision-makers may be involved in assigning weighting values and a discursive approach is recommended.

Then, the evaluation score for each of the circularity strategies against each sub-criteria/decision factor and indicator both for the qualitative and quantitative factors is calculated. In this step, a scale-based parameter value (5-Very high; 4-High; 3-Average; 2-Low; 1-Very low) can be assigned for the qualitative decision factors such as business, technical, societal, and legislative. LCA and LCC can, for example, be performed to evaluate the environmental and economic performance for the quantitative indicators respectively. As discussed in Section 4.3, these criteria, sub-criteria and indicators can be changed depending on the preferences of the decision-maker(s) as well as the availability of data and related factors.

Afterward, relative weighting (normalization) is conducted to allow a comparable scale for all circular strategies using Equations (2) and (3). Depending on the typical problem, Equation (2) is used when the objective of the problem is to maximize the result and Equation (3) is used when the objective is to minimize the result.

The normalization for maximization problem:

$$
\mathrm{N}=\mathrm{X}_{\mathrm{ij}} / \mathrm{X}_{\mathrm{ij} \max }
$$

The normalization for minimization problem:

$$
\mathrm{N}=\mathrm{X}_{\mathrm{ij} \min } / \mathrm{X}_{\mathrm{ij}}
$$

where:

$X_{\mathrm{ij}}$ is the assigned value of Ai for the sub-criteria C $\mathrm{jk}$ $X_{\mathrm{ij} \mathrm{max}} ; X_{\mathrm{ij} \text { min }}$ are the maximum and minimum assigned value $A_{i}$ for the sub-criteria $C_{j}$ respectively.

Finally, the overall score of each circularity strategy is computed based on Equation (4) and ranked the result in descending order.

$$
M_{(A i)}=\Sigma W_{j} X_{i(j)}, j=1,2, \ldots m, i=1,2, \ldots, n,
$$

where:

$W_{j}$ is the weighted value of $j$ of $m$ criteria

$X_{i(j)}$ is the value of $i$ of criterion $j$

$\mathrm{M}_{(\mathrm{Ai})}$ is total evaluation result for each strategy. 


\subsection{Analysis of the Result and Recommendation}

This step involves analyzing the overall score of each of the circularity strategies and providing recommendations concerning the circularity strategies from the available list of alternatives. The main elements and outcomes of the evaluation method for the user (decision-maker) are depicted in Figure 3.

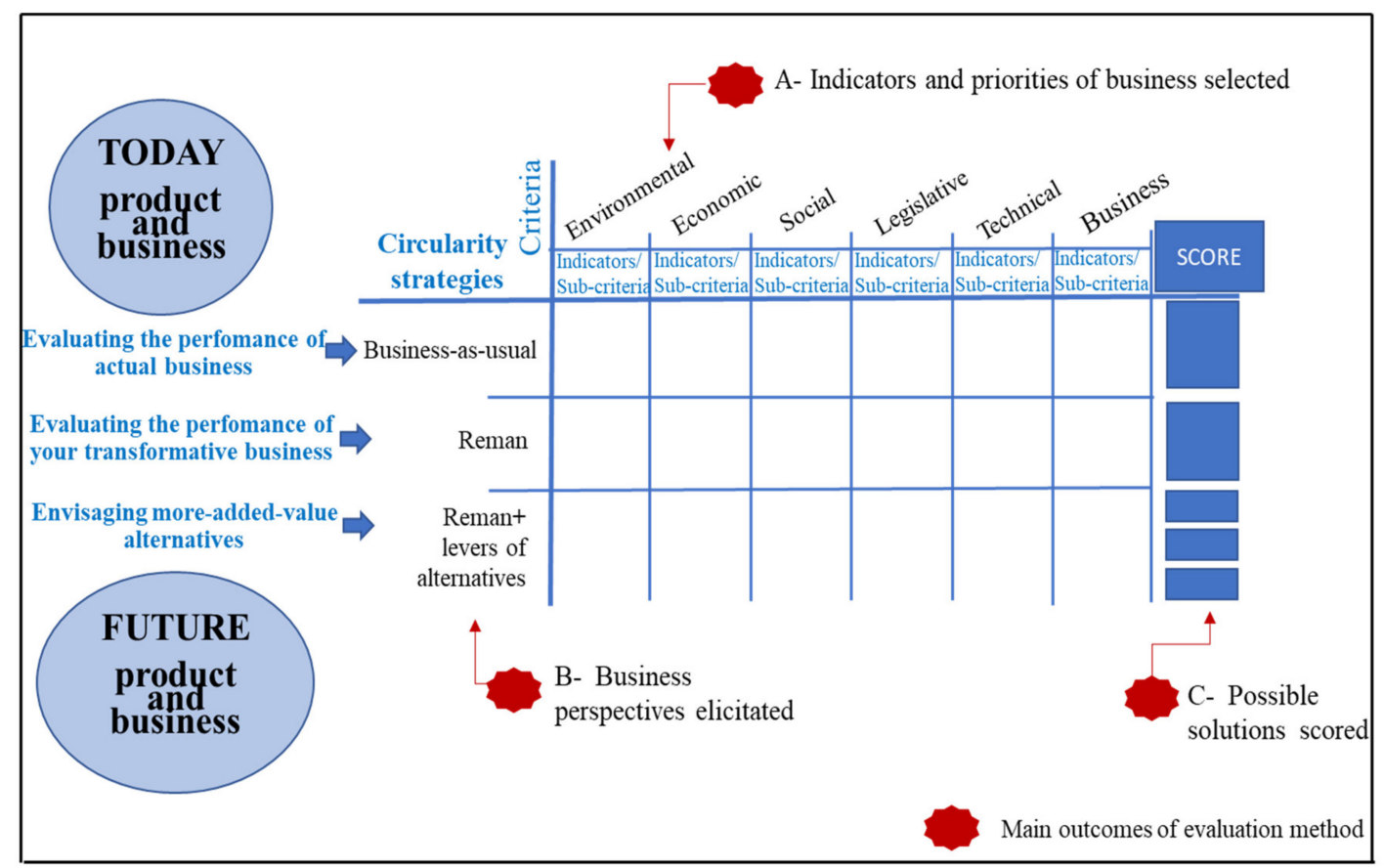

Figure 3. Graphical repreesentaion of main outcomes of the evaluation method.

\section{Verification of the Multi-Criteria Evaluation Method of Product-Level Circularity Strategies}

The proposed circularity strategies' evaluation method is verified through two illustrative examples with two case studies. Secondary data collected from two companies is used to verify the application of the proposed method to evaluate alternative circularity strategies. More details about the case study companies can be found from Kaddoura, Kambanou, Tillman, and Sakao (2019) [81]. In the following sections, the application of the proposed method to each case company is presented.

\subsection{Case Study for Company A}

Company A offers vacuum waste collection system for residential areas, business premises, and town centers worldwide. The collection system transports the waste through an underground pipeline and into a sealed container. In addition to product planning and installation, the company provides various services including maintenance. This study focuses on the inlet part of the waste collection system due to frequent failure.

In this study, three business strategies are considered: Business-as-usual (when the inlet breaks, the whole door is replaced); circular strategy 1 (when the inlet breaks, broken parts of the door are replaced with new parts, and parts of the door that are not broken are reused); and circular strategy 2 (when the inlet breaks, parts of the door that are not broken are reused to make new doors). Table 3 shows a description of circularity strategies for Company A.

The multi-criteria evaluation method has six main criteria to evaluate potential circularity strategies: Environmental, economic, social, legislative, technical, and business. The sub-criteria and indicators under each criterion, which are used in this research are LCA, LCC, job creation opportunity, legislative pressure, technical feasibility (for instance, ease of disassembly, technological compatibility, etc.) and market demand respectively. Additionally, a weighting value of 0.15, 0.20, 0.10, 0.15, 0.20, 0.20 (based on experience from previous study in [49] and [81]) is assigned respectively as shown in Table 4. 
Table 3. Description of circularity strategies for case study A.

\begin{tabular}{ll}
\hline \multicolumn{1}{c}{ List of Strategies } & \multicolumn{1}{c}{ Description } \\
\hline $\begin{array}{l}\text { Business-as-usual (BAU) } \\
\text { The vacuum waste systems are installed based on } \\
\text { contracts and remote control and regular } \\
\text { maintenance is conducted during the use phase. } \\
\text { When the inlet breaks, the whole door is replaced, } \\
\text { and the post-used product is mostly recycled. }\end{array}$ \\
$\begin{array}{ll}\text { (Circular strategy 1) (Transformative } \\
\text { strategy) (Repair) }\end{array}$ \\
$\begin{array}{l}\text { Same as BAU but when the inlet breaks, broken parts } \\
\text { of the door are repaired by service technicians } \\
\text { (broken parts of the door are replaced with new parts } \\
\text { and parts of the door that are not broken are reused). }\end{array}$ \\
$\begin{array}{l}\text { (Circular strategy 2) (Future strategy) } \\
\text { (Remanufacturing) }\end{array}$ & $\begin{array}{l}\text { Same as circular strategy 1 but when the inlet breaks, } \\
\text { parts of the door that are not broken are reused to } \\
\text { make new doors in which the quality of the product } \\
\text { is equivalent to a newly manufactured product. }\end{array}$ \\
\hline
\end{tabular}

Table 4. Evaluation of circularity strategies for Company A.

\begin{tabular}{|c|c|c|c|c|c|}
\hline \multicolumn{3}{|c|}{ Circularity Strategies } & \multirow{2}{*}{ Business-as-Usual } & \multirow{2}{*}{$\begin{array}{l}\text { Circular } \\
\text { Strategy } 1\end{array}$} & \multirow{2}{*}{$\begin{array}{c}\text { Circular } \\
\text { Strategy } 2\end{array}$} \\
\hline Criteria & Sub-Criteria/Indicator & Weight $\left(W_{j}\right)$ & & & \\
\hline \multirow{6}{*}{ Environmental Normalization (N) } & \multirow{2}{*}{ LCA (GWP100—-kg CO 2 eq.) } & \multirow{6}{*}{0.15} & 1545 & 1545 & 1525 \\
\hline & & & 0.98 & 0.98 & 1 \\
\hline & (kg SO$)_{2}$ eq.) & & 7.2 & 7 & 6.8 \\
\hline & 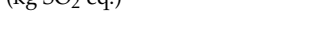 & & 0.94 & 0.97 & 1 \\
\hline & ( $\mathrm{kg} \mathrm{PO}_{4}$ eq. $)$ & & 4.3 & 4.3 & 4.3 \\
\hline & ( $\mathrm{Kg} \mathrm{PO}_{4}$ eq.) & & 1 & 1 & 1 \\
\hline \multirow{2}{*}{ Economic Normalization (N) } & \multirow{2}{*}{ LCC (Provider's profit (SEK)) ${ }^{1}$} & \multirow{2}{*}{0.20} & 22,350 & 21,100 & 21,600 \\
\hline & & & 1 & 0.94 & 0.97 \\
\hline \multirow{2}{*}{ Social Normalization (N) } & \multirow{2}{*}{ Job creation opportunity (a) } & \multirow{2}{*}{0.10} & 4 & 4 & 5 \\
\hline & & & 0.8 & 0.8 & 1 \\
\hline \multirow{2}{*}{ Legislative Normalization (N) } & \multirow{2}{*}{ Effect of legislative pressure (a) } & \multirow{2}{*}{0.15} & 5 & 3 & 1 \\
\hline & & & 0.2 & 0.33 & 1 \\
\hline \multirow{2}{*}{ Technical Normalization (N) } & \multirow{2}{*}{$\begin{array}{l}\text { Technical feasibility e.g., } \\
\text { disassembly (a) }\end{array}$} & \multirow{2}{*}{0.20} & 2 & 4 & 5 \\
\hline & & & 0.4 & 0.8 & 1 \\
\hline \multirow{2}{*}{ Business Normalization (N) } & \multirow{2}{*}{ Market demand (a) } & \multirow{2}{*}{0.20} & 3 & 5 & 5 \\
\hline & & & 0.6 & 1 & 1 \\
\hline \multirow{2}{*}{ Total (without Wi) Total (with Wi) } & & \multirow{2}{*}{1.00} & 3.97 & 4.85 & 5.97 \\
\hline & & & 0.66 & 0.82 & 0.99 \\
\hline
\end{tabular}

${ }^{1}$ The numbers for the indicator "provider's profit" are confidential and therefore, these numbers have been multiplied/divided by a random factor in order to ensure comparability. (a) Parameter value: 5-Very high; 4-High; 3-Average; 2-Low; 1-Very low.

Based on the result of the analysis, remanufacturing (circular strategy 2) of the waste collection system got the highest score followed by circular strategy 1 and is the most suitable circularity strategy. The results of the analysis are presented in Table 4.

To read Table 4, each row represents a criterion and its value for each of the three alternative strategies under consideration (UP is the real value for quantitative sub-criteria and the value in a scale of 1-5 for qualitative sub-criteria; DOWN is the same result normalized from 1 for the best score). Each column represents one of the three alternative strategies studied, and in the last row, the final score against all the criteria is given. Some comments can be drawn for the results. Firstly, the result would have been similar $(0.66,0.82,0.99$ respectively) if the weighting value is assumed to be equal for all criteria. Secondly, considering a higher weight value for economic criteria, if the analysis is performed only against environmental and economic criteria, the preferred strategy would have been the business-as-usual option. This has happened due to the company A's pricing system and the estimation of customers' willingness to pay; even though, the bulk selling effect of the product shows an increase in profit margin.

\subsection{Case Study for Company B}

Company B is a supplier of storage furniture. The company supplies furniture, recycling stations, wardrobes, etc. These products are sold to the customers and there is no added value on the product sold, such as services. 
In this study, two business strategies are considered: Business-as-usual (the product is sold to the customer and the customer is responsible for disposal of the product at the EoL phase), and upgrade (the product is upgraded by refreshing products' appearance). In the circular strategy, the company is also in charge of administering and coordinating the upgrading process. Table 5 shows a description of circularity strategies considered for Company B.

Table 5. Description of circularity strategies for Company B.

\begin{tabular}{ll}
\hline \multicolumn{1}{c}{ List of Strategies } & \multicolumn{1}{c}{ Description } \\
\hline Business-as-usual & $\begin{array}{l}\text { The product is sold to the customer. The customer is responsible for } \\
\text { disposal of the product when it reaches its EoL phase. }\end{array}$ \\
\hline Circular strategy (upgrading) & $\begin{array}{l}\text { The product is upgraded by refreshing products' appearance and } \\
\text { therefore, its operational life for the customer is doubled. The company } \\
\text { is responsible for providing the intended service. }\end{array}$ \\
\hline
\end{tabular}

Case studies A and B use the same criteria and sub-criteria to evaluate circularity strategies. In this case study, a weighting value of $0.15,0.20,0.10,0.15,0.20,0.20$ (based on experience from the previous study by Alamerew and Brissaud [49] and [81]) is assigned respectively as shown in Table 6.

Table 6. Evaluation of circularity strategies for case study B.

\begin{tabular}{|c|c|c|c|c|}
\hline \multicolumn{3}{|c|}{ Circularity Strategies } & \multirow{2}{*}{ Business-as-Usual } & \multirow{2}{*}{ Circular Strategy } \\
\hline Criteria & Sub-Criteria & Weight $\left(W_{j}\right)$ & & \\
\hline \multirow{6}{*}{ Environmental Normalization (N) } & \multirow[t]{2}{*}{ LCA (GWP100—-kg CO 2 eq.) } & \multirow{6}{*}{0.15} & 230 & 125 \\
\hline & & & 0.53 & 1.00 \\
\hline & \multirow{2}{*}{ (kg SO 2 eq.) } & & 1.35 & 0.70 \\
\hline & & & 0.52 & 1.00 \\
\hline & \multirow{2}{*}{ (kg $\mathrm{PO}_{4}$ eq.) } & & 0.40 & 0.20 \\
\hline & & & 0.50 & 1.00 \\
\hline \multirow{2}{*}{ Economic Normalization (N) } & \multirow{2}{*}{ LCC (Provider's profit (SEK)) ${ }^{2}$} & \multirow{2}{*}{0.20} & 550 & 600 \\
\hline & & & 0.90 & 1.00 \\
\hline \multirow{2}{*}{ Social Normalization $(\mathrm{N})$} & \multirow{2}{*}{ Job creation opportunity (a) } & \multirow{2}{*}{0.10} & 2 & 4 \\
\hline & & & 0.5 & 1 \\
\hline \multirow{2}{*}{ Legislative Normalization (N) } & \multirow{2}{*}{ Effect of legislative pressure (a) } & \multirow{2}{*}{0.15} & 2 & 3 \\
\hline & & & 0.66 & 1 \\
\hline \multirow{2}{*}{ Technical Normalization (N) } & \multirow{2}{*}{ Technical feasibility e.g., disassembly (a) } & \multirow{2}{*}{0.20} & 2 & 5 \\
\hline & & & 0.4 & 1 \\
\hline \multirow{2}{*}{ Business Normalization (N) } & \multirow{2}{*}{ Market demand (a) } & \multirow{2}{*}{0.20} & 3 & 4 \\
\hline & & & 0.75 & 1 \\
\hline \multirow{2}{*}{ Total (without $\mathrm{W}_{\mathrm{i}}$ ) Total (with $\mathrm{W}_{\mathrm{i}}$ ) } & & \multirow{2}{*}{1.00} & 3.73 & 6.00 \\
\hline & & & 0.63 & 1.00 \\
\hline
\end{tabular}

2 The numbers for the indicator "provider's profit" are confidential and therefore, these numbers have been multiplied by a random factor in order to ensure comparability. (a) Parameter value: 5-Very high; 4-High; 3-Average; 2-Low; 1-Very low.

Based on the results of the analysis as presented in Table 6, upgrading the product is a suitable strategy. The study shows that the circular offering, i.e., upgrading, is a preferred strategy over the business-as-usual scenario. As opposed to the case study A, here, the weighting system does not influence the results because the circular strategy performs better against all criteria.

\section{Discussion and Conclusions}

\subsection{Discussion}

One of the challenges that impede companies from transforming their business towards a CE model is the lack of methods, tools, and indicators to be able to evaluate different circularity strategies. In this article, a multi-criteria evaluation method of circularity strategies for products and/or services has been developed and verified. This method can be implemented at EoL phase by the company providing the initial product and third-party recovery/remanufacturing companies. 
One of the limitations of this MCDM method is a lack of linkages between the criteria. MCDM is characterized by criteria independence without correlation [83]. Due to the complexity of CE, it is imperative to understand the interaction (direct or indirect dependency) among decision factors in the decision-making process.

There is also a risk with MCDM, that sub-criteria and indicators present overlaps so the effect of a decision gets double-counted or that they do not comprehensively cover a criterion so some effects are not taken into account when making a decision [22]. Moreover, MCDM uses qualitative indicators. The assignment of verbal grading to these indicators and its conversion into a parameter value based on a qualitative scale is subject to ambiguity. When assigning weighing values to criteria, it may be difficult for the decision-maker to decide which of the criteria have more influence and to quantify this influence for the circularity alternatives. To minimize but not eliminate these risks, it is recommended that relevant stakeholders and decision-makers deliberate over and jointly discuss various choices, e.g., indicator choice, grading, and weighting.

In order to transform the qualitative criteria into quantitative numbers, a rating scale is used. In this study, a semantic scale, Likert, is recommended as it is commonly used in business decision-making [84,85]. A scoring scale from 1 to 5 is used to quantify the qualitative factors. Theoretically, the numerical scale/verbal grading cannot be restricted, and other scales can be used following investigation.

The proposed method uses an integrated approach to evaluate the environmental and economic benefits of circularity strategies together with social, legislative, business and technical aspects. An illustrative example through the two case studies is presented which shows that the proposed method is simple and effective in dealing with circularity strategy evaluation problems. The case studies demonstrate the process of evaluating CE strategies at the EoL phase of the product. However, the case examples lack in demonstrating the broader impact of each strategy due to the implementation of circular practices across the product life cycle such as the continuous flow of products, components, materials and information, as well as the application of service offering. This can be analyzed by studying the environmental, economic and social benefit for the company and the resulting outcome due to the implementation of circularity strategies.

The results from the cases demonstrate that the method can identify not only differences between business-as-usual and circularity strategies, but also between different types of circularity strategies. Compared to Alamerew and Brissaud (2018) [49], this method evaluates and compares the initial business of the company, a transformative strategy that transforms a product through the implementation of advanced circularity strategies and future circular strategies.

Some of the main benefits of the proposed method are:

- It guides the decision-makers through the whole process of identifying and evaluating various potential circularity strategies against each other and business-as-usual.

- It helps companies identify potential circular offerings and strategies.

- It suggests a list of criteria and sub-criteria/indicators which are relevant for evaluating circular strategies, but also allows for flexibility so that the decision-maker can modify these criteria and provides insights on how to approach such modifications.

- It can be used to evaluate and compare a large number of circular strategies.

- It is a flexible method that can easily be scaled up or down to meet the needs of the decision-makers.

Finally, by using this method, more companies may be encouraged to implement circularity strategies. This can reduce the environmental impacts associated with their products and/or services, and thereby potentially contribute to relative resource decoupling [86]. Of course, there is always a risk of rebound effects so it might not necessarily lead to absolute resource decoupling (ibid.). Therefore, a limitation of this evaluation method is that it does not take into consideration rebound effects.

This evaluation method, however, can even help companies who are, as Matschewsky (2019) [87] describes it, unintentionally contributing to relative resource decoupling to evaluate their contributions. 
These are companies that have pursued circular strategies as good business without having considered their environmental and other benefits.

\subsection{Conclusions and Future Research}

Evaluation of circularity strategies is crucial to select appropriate strategies and move towards a CE. Even though various methods and indicators have been developed by academics to measure the progress towards CE, there is a lack of circularity strategies' evaluation methods at the product level $[13,21]$. Therefore, in this article, a multi-criteria evaluation method of product-level circularity strategies is developed. Its contribution lies in the multi-criteria approach that can address the complexity of such an evaluation, and support decision-making by taking into account both how a circularity strategy performs with respect to the CE principles and how feasible the strategy is. This is done by providing a list of recommended criteria, sub-criteria and indicators while still allowing companies to modify them based on their specific case. The application and usefulness of the proposed evaluation method are demonstrated by applying it on two cases: a vacuum waste collection system and office furniture.

Although this research has contributed to filling some of the research gaps presented in Section 1 , further investigations are required. One future research path is to use the proposed method for various types of products, services, and industrial sectors together with practitioners. This helps to generalize the application of the proposed method to various industrial sectors. Moreover, it could be interesting to compare and analyze the results across various industrial sectors. This helps to learn from successful experiences so that one industrial sector can learn from other sectors in an effort to transform to a CE. In addition, more research could be conducted to test the proposed method on first-hand company data.

Another important research opportunity could be to extend the proposed evaluation method to include pre-use/use phase of the product/service, e.g., production energy efficiency measures. This method evaluates a post-use product/service at the EoL phase. Furthermore, the environmental, economic and social benefit of the strategies for the company and the resulting outcome could be studied due to the implementation of circularity strategies. Along this line, apart from zooming out to include more types of circular strategies, further research could zoom in to identify sub-criteria and indicators that target specific circular strategies or product groups, e.g., reuse. Moreover, the interaction between criteria and sub-criteria and their influence on the overall result from a system perspective should be studied in the future. One approach to address this gap would be to use Analytical Network Process (ANP) to understand the inter-dependency among decision factors.

Author Contributions: Conceptualization, Y.A.A. and M.L.K; methodology, Y.A.A. and T.S.; validation, Y.A.A.; formal analysis, Y.A.A.; resources, M.L.K.; data curation, Y.A.A.; writing—original draft preparation, Y.A.A. and M.L.K.; writing-review and editing, Y.A.A., M.L.K., D.B. and T.S.; visualization, Y.A.A.; supervision, D.B. and T.S.; project administration, M.L.K., D.B. and T.S.; funding acquisition, D.B. and T.S. All authors have read and agreed to the published version of the manuscript.

Funding: This research was fully funded by the "Marie Sklodowska-Curie Innovative Training Network "Circ€uit": Circular European Economy Innovative Training Network", within Horizon 2020 Programme of the European Commission (grant number 721909). Moreover, we acknowledge the support of the Circularis (Circular Economy through Innovation Design) project (no. 2016-03267), funded by VINNOVA, Sweden's Innovation Agency.

Conflicts of Interest: The authors declare no conflict of interest.

\section{References}

1. Niskanen, J.; Anshelm, J.; McLaren, D. Local conflicts and national consensus: The strange case of circular economy in Sweden. J. Clean. Prod. 2020, 261, 121117. [CrossRef]

2. Geissdoerfer, M.; Savaget, P.; Bocken, N.M.P.; Hultink, E.J. The Circular Economy-A new sustainability paradigm? J. Clean. Prod. 2017, 143, 757-768. [CrossRef]

3. Rosa, P.; Sassanelli, C.; Urbinati, A.; Chiaroni, D.; Terzi, S. Assessing relations between Circular Economy and Industry 4.0: A systematic literature review. Int. J. Prod. Res. 2020, 58, 1662-1687. [CrossRef] 
4. Fellner, J.; Lederer, J.; Scharff, C.; Laner, D. Present potentials and limitations of a circular economy with respect to primary raw material demand. J. Ind. Ecol. 2017, 21, 494-496. [CrossRef]

5. EMF. Towards the Circular Economy: Economic and Business Rationale for an Accelerated Transition; EMF: Cowes, UK, 2013.

6. Gitelman, L.; Magaril, E.; Kozhevnikov, M.; Rada, E.C. Rational behavior of an enterprise in the energy market in a circular economy. Resources 2019, 8, 73. [CrossRef]

7. Webster, K. The Circular Economy: A Wealth of Flows; Ellen MacArthur Foundation: Cowes, UK, 2015.

8. Bocken, N.M.P.; Olivetti, E.A.; Cullen, J.M.; Potting, J.; Lifset, R. Taking the Circularity to the Next Level: A Special Issue on the Circular Economy. J. Ind. Ecol. 2017, 21, 476-482. [CrossRef]

9. Elia, V.; Gnoni, M.G.; Tornese, F. Measuring circular economy strategies through index methods: A critical analysis. J. Clean. Prod. 2017, 142, 2741-2751. [CrossRef]

10. Saidani, M.; Yannou, B.; Leroy, Y.; Cluzel, F.; Kendall, A. A taxonomy of circular economy indicators. J. Clean. Prod. 2019, 207, 542-559. [CrossRef]

11. Kirchherr, J.; Piscicelli, L.; Bour, R.; Kostense-Smit, E.; Muller, J.; Huibrechtse-Truijens, A.; Hekkert, M. Barriers to the circular economy: Evidence from the European Union (EU). Ecol. Econ. 2018, 150, $264-272$. [CrossRef]

12. Rizos, V.; Behrens, A.; van der Gaast, W.; Hofman, E.; Ioannou, A.; Kafyeke, T.; Flamos, A.; Rinaldi, R.; Papadelis, S.; Hirschnitz-Garbers, M.; et al. Implementation of circular economy business models by small and medium-sized enterprises (SMEs): Barriers and enablers. Sustainability 2016, 8, 1212. [CrossRef]

13. Kristensen, H.S.; Mosgaard, M.A. A review of micro level indicators for a circular economy-Moving away from the three dimensions of sustainability? J. Clean. Prod. 2020, 243, 118531. [CrossRef]

14. Bianchini, A.; Rossi, J.; Pellegrini, M. Overcoming the main barriers of circular economy implementation through a new visualization tool for circular business models. Sustainability 2019, 11, 6614. [CrossRef]

15. Geng, Y.; Fu, J.; Sarkis, J.; Xue, B. Towards a national circular economy indicator system in China: An evaluation and critical analysis. J. Clean. Prod. 2012, 23, 216-224. [CrossRef]

16. Linder, M.; Sarasini, S.; Loon, P. Van A metric for quantifying product-level circularity. J. Ind. Ecol. 2017, 21, 545-558. [CrossRef]

17. Cayzer, S.; Griffiths, P.; Beghetto, V. Design of indicators for measuring product performance in the circular economy. Int. J. Sustain. Eng. 2017, 7038, 289-298. [CrossRef]

18. Huysman, S.; Schaepmeester, J.D.; Ragaert, K.; Dewulf, J.; Meester, S. De Resources, conservation and recycling performance indicators for a circular economy: A case study on post-industrial plastic waste. Resour. Conserv. Recycl. 2017, 120, 46-54. [CrossRef]

19. Parchomenko, A.; Nelen, D.; Gillabel, J.; Rechberger, H. Measuring the circular economy-A multiple correspondence analysis. J. Clean. Prod. 2019, 210, 200-216. [CrossRef]

20. Sassanelli, C.; Rosa, P.; Rocca, R.; Terzi, S. Circular economy performance assessment methods: A systematic literature review. J. Clean. Prod. 2019, 229, 440-453. [CrossRef]

21. Saidani, M.; Yannou, B.; Leroy, Y.; Cluzel, F. How to assess product performance in the circular economy? Proposed requirements for the design of a circularity measurement framework. Recycling 2017, 2, 6. [CrossRef]

22. Lindfors, A.; Feiz, R.; Eklund, M.; Ammenberg, J. Assessing the potential, performance and feasibility of urban solutions: Methodological considerations and learnings from biogas solutions. Sustainability 2019, 11, 3756. [CrossRef]

23. Ali, M.; Kennedy, C.M.; Kiesecker, J.; Geng, Y. Integrating biodiversity offsets within circular economy policy in China. J. Clean. Prod. 2018, 185, 32-43. [CrossRef]

24. Pesce, M.; Tamai, I.; Guo, D.; Critto, A.; Brombal, D.; Wang, X.; Cheng, H.; Marcomini, A. Circular Economy in China: Translating Principles into Practice. Sustainability 2020, 12, 832. [CrossRef]

25. Kirchherr, J.; Reike, D.; Hekkert, M. Conceptualizing the circular economy: An analysis of 114 definitions. Resour. Conserv. Recycl. 2017, 127, 221-232. [CrossRef]

26. Ellen MacArthur Foundation and Granta Design. An Approach to Measuring Circularity; Ellen MacArthur Foundation and Granta Design: Cowes, UK, 2015.

27. Stahel, W.R. The circular economy. Nature 2016, 531, 435-438. [CrossRef]

28. Bakker, C.; den Hollander, M.; Van Hinte, E.; Zljlstra, Y. Products That Last: Product Design for Circular Business Models; TU Delft Library: Delft, The Netherlands, 2014. 
29. Niu, S.; Zhuo, H.; Xue, K. DfRem-Driven closed-loop supply chain decision-making: A systematic framework for modeling research. Sustainability 2019, 11, 3299. [CrossRef]

30. Hopkinson, P.; De Angelis, R.; Zils, M. Systemic building blocks for creating and capturing value from circular economy. Resour. Conserv. Recycl. 2020, 155, 104672. [CrossRef]

31. Levänen, J.; Lyytinen, T.; Gatica, S. Modelling the Interplay Between Institutions and Circular Economy Business Models: A Case Study of Battery Recycling in Finland and Chile. Ecol. Econ. 2018, 154, 373-382. [CrossRef]

32. Alamerew, Y.A.; Brissaud, D. Modelling reverse supply chain through system dynamics for realizing the transition towards the circular economy: A case study on electric vehicle batteries. J. Clean. Prod. 2020, 254, 120025. [CrossRef]

33. Sangwan, K.S. Key activities, decision variables and performance indicators of reverse logistics. Procedia CIRP 2017, 61, 257-262. [CrossRef]

34. Julianelli, V.; Caiado, R.G.G.; Scavarda, L.F.; Cruz, S.P.D.M.F. Interplay between reverse logistics and circular economy: Critical success factors-based taxonomy and framework. Resour. Conserv. Recycl. 2020, 158, 104784. [CrossRef]

35. Korhonen, J.; Nuur, C.; Feldmann, A.; Seyoum Eshetu, B. Circular economy as an essentially contested concept. J. Clean. Prod. 2018, 175, 544-552. [CrossRef]

36. Di Maio, F.; Rem, P.C. A Robust Indicator for Promoting Circular Economy through Recycling. J. Environ. Prot. 2015, 06, 1095-1104. [CrossRef]

37. Brissaud, D.; Zwolinski, P. The Scientific Challenges for a Sustainable Consumption and Production Scenario: The Circular Reuse of Materials for the Upgrading and Repurposing of Components. Procedia CIRP 2017, 61, 663-666. [CrossRef]

38. Richa, K.; Babbitt, C.W.; Gaustad, G.; Wang, X. A future perspective on lithium-ion battery waste flows from electric vehicles. Resour. Conserv. Recycl. 2014, 83, 63-76. [CrossRef]

39. Burke, A. Performance, Charging, and Second-Use Considerations for Lithium Batteries for Plug-In Electric Vehicles; UC Davis Institute of Transportation Studies: Davis, CA, USA, 2009.

40. Winslow, K.M.; Laux, S.J.; Townsend, T.G. A review on the growing concern and potential management strategies of waste lithium-ion batteries. Resour. Conserv. Recycl. 2018, 129, 263-277. [CrossRef]

41. King, A.M.; Burgess, S.C.; Ijomah, W.; McMahon, C.A. Reducing waste: Repair, recondition, remanufacture or recycle? Sustain. Dev. 2006, 14, 257-267. [CrossRef]

42. Krikke, H.R. Recovery Strategies and Reverse Logistic Network Design. Ph.D. Thesis, University of Twente, Enschede, The Netherlands, 1998.

43. Paterson, D.A.P.; Ijomah, W.L.; Windmill, J.F.C. End-of-Life decision tool with emphasis on remanufacturing. J. Clean. Prod. 2017, 148, 653-664. [CrossRef]

44. Ijomah, W.L. A Model-Based Definition of The Generic Remanufacturing Business Process; University of Plymouth: Plymouth, UK, 2002.

45. Rose, C.M. Design for Environment: A Method for Formulating End-of-Life Strategies. Ph.D. Thesis, Stanford University, Stanford, CA, USA, 2000.

46. Sundin, E. Product and Process Design for Successful Remanufacturing. Ph.D. Thesis, Linköping University, Linköping, Sweden, 2004.

47. Bauer, T.; Brissaud, D.; Zwolinski, P. Design for High Added-Value End-of-Life Strategies. In Sustainable Manufacturing; Springer: Cham, Switzerland, 2017; ISBN 978-3-319-48513-3.

48. Kurt, A.; Cung, V.; Mangione, F.; Cortes-Cornax, M.; Front, A. An extended circular supply chain model including repurposing activities. In Proceedings of the International Conference on Control, Automation and Diagnosis (ICCAD), Grenoble, France, 2-4 July 2019; pp. 1-6.

49. Alamerew, Y.A.; Brissaud, D. Circular economy assessment tool for end of life product recovery strategies. J. Remanuf. 2018, 9, 169-185. [CrossRef]

50. Jawahir, I.S.; Bradley, R. Technological elements of circular economy and the principles of 6R-based closed-loop material flow in sustainable manufacturing. Procedia Cirp 2016, 40, 103-108. [CrossRef]

51. Widmer, T.; Tjahjono, B.; Bourlakis, M. Defining value creation in the context of circular PSS. Procedia CIRP 2018, 73, 142-147. [CrossRef]

52. Kumar, V.; Shirodkar, P.S.; Camelio, J.A.; Sutherland, J.W. Value flow characterization during product lifecycle to assist in recovery decisions. Int. J. Prod. Res. 2007, 45, 18-19. [CrossRef] 
53. Thierry, M.; Salomon, M.; Vannunen, J.; Vanwassenhove, L. Strategic Issues in Product Recovery Management. Calif. Manag. Rev. 1995, 37, 114-135. [CrossRef]

54. Ghisellini, P.; Cialani, C.; Ulgiati, S. A review on circular economy: The expected transition to a balanced interplay of environmental and economic systems. J. Clean. Prod. 2016, 114, 11-32. [CrossRef]

55. Kambanou, M.L.; Sakao, T. Using life cycle costing (LCC) to select circular measures: A discussion and practical approach. Resour. Conserv. Recycl. 2020, 155, 104650. [CrossRef]

56. Mont, O.; Plepys, A.; Whalen, K.; Nußholz, J.L. Business Model Innovation For a Circular Economy: Drivers and Barriers for the Swedish Industry-the Voice of REES Companies; Lund University Publications: Lund, Sweden, 2017.

57. Babbitt, C.W.; Gaustad, G.; Fisher, A.; Chen, W.-Q.; Liu, G. Closing the loop on circular economy research: From theory to practice and back again. Resour. Conserv. Recycl. 2018, 135, 1-2. [CrossRef]

58. Pauliuk, S. Critical appraisal of the circular economy standard BS 8001:2017 and a dashboard of quantitative system indicators for its implementation in organizations. Resour. Conserv. Recycl. 2018, 129, 81-92. [CrossRef]

59. Blomsma, F.; Pieroni, M.; Kravchenko, M.; Pigosso, D.C.A.; Hildenbrand, J.; Kristinsdottir, A.R.; Kristoffersen, E.; Shahbazi, S.; Nielsen, K.D.; Jönbrink, A.-K.; et al. Developing a circular strategies framework for manufacturing companies to support circular economy-oriented innovation. J. Clean. Prod. 2019, 241, 118271. [CrossRef]

60. Saidani, M.; Yannou, B.; Leoroy, Y.; Cluzel, F. Hybrid top-down and bottom-up framework to measure products' circularity performance. In Proceedings of the 21st International conference on engineering design, ICED17, Vancover, BC, Canada, 21-25 August, 2017; Volume 1, pp. 81-90.

61. Doyle, K.; Ijomah, W.L.; Antony, J. Identifying the End of Life Decision Making Factors. In Design for Innovative Value Towards a Sustainable Society; Springer: Dordrecht, The Netherlands, 2012; pp. 530-534. [CrossRef]

62. Dunmade, I. PLETS model: A sustainability concept based approach to product end-of-life management. In Proceedings of the Environmentally Conscious Manufacturing IV; Surendra, M.G., Ed.; International Society for Optics and Photonics: Bellingham, WA, USA, 2004; Volume 5583, pp. 118-126.

63. Shih, L.H.; Chang, Y.S.; Lin, Y.T. Intelligent evaluation approach for electronic product recycling via case-based reasoning. Adv. Eng. Informatics 2006, 20, 137-145. [CrossRef]

64. Selmi, M.; Kormi, T.; Bel Hadj Ali, N. Comparison of multi-criteria decision methods through a ranking stability index. Int. J. Oper. Res. 2016, 27, 165. [CrossRef]

65. Velasquez, M.; Hester, P.T. An analysis of multi-criteria decision making methods. Int. J. Oper. Res. 2013, 10, $56-66$.

66. ResCoM Resource Conservative Manufacturing Project. Available online: https://rescomd58.eurostep.com/ idealco/pathfinder/ (accessed on 5 March 2020).

67. Lee, H.M.; Lu, W.F.; Song, B. A framework for assessing product end-of-life performance: Reviewing the state of the art and proposing an innovative approach using an end-of-life index. J. Clean. Prod. 2014, 66, 355-371. [CrossRef]

68. Evans, J.; Bocken, N.M.P. Circular Economy Toolkit. Available online: http://circulareconomytoolkit.org/ index.html (accessed on 16 July 2019).

69. Iakovou, E.; Moussiopoulos, N.; Xanthopoulos, A.; Achillas, C.; Michailidis, N.; Chatzipanagioti, M.; Koroneos, C.; Bouzakis, K.D.; Kikis, V. A methodological framework for end-of-life management of electronic products. Resour. Conserv. Recycl. 2009, 53, 329-339. [CrossRef]

70. Mardani, A.; Jusoh, A.; Nor, K.M.D.; Khalifah, Z.; Zakwan, N.; Valipour, A. Multiple criteria decision-making techniques and their applications-A review of the literature from 2000 to 2014. Econ. Res. Istraz. 2015, 28, 516-571. [CrossRef]

71. Macoun, P.; Prabhu, R. Guidelines for Applying Multi-Criteria Analysis to The Assessment of Criteria and Indicators; CIFOR: Bogor, Indonesia, 1999.

72. Feiz, R.; Ammenberg, J. Assessment of feedstocks for biogas production, part I-A multi-criteria approach. Resour. Conserv. Recycl. 2017, 122, 373-387. [CrossRef]

73. Dijk, M.; de Kraker, J.; van Zeijl-Rozema, A.; van Lente, H.; Beumer, C.; Beemsterboer, S.; Valkering, P. Sustainability assessment as problem structuring: Three typical ways. Sustain. Sci. 2017, 12, 305-317. [CrossRef] 
74. Siregar, D.; Arisandi, D.; Usman, A.; Irwan, D.; Rahim, R. Research of Simple Multi-Attribute Rating Technique for Decision Support. J. Phys. Conf. Ser. 2017, 930. [CrossRef]

75. Risawandi, R.R. Study of the Simple Multi-Attribute Rating Technique For Decision Support. IJSRST 2016, 2, 491-494.

76. Taylor, J.M.; Love, B.N. Simple multi-attribute rating technique for renewable energy deployment decisions (SMART REDD). J. Def. Model. Simul. Appl. Methodol. Technol. 2014, 11, 227-232. [CrossRef]

77. Böckin, D.; Willskytt, S.; André, H.; Tillman, A.-M.; Ljunggren Söderman, M. How product characteristics can guide measures for resource efficiency-A synthesis of assessment studies. Resour. Conserv. Recycl. 2020, 154, 104582. [CrossRef]

78. Roy, B. Multicriteria Methodology for Decision Aiding; Springer Science \& Business Media: Berlin/Heideberg, Germany, 1996.

79. Bocken, N.; Strupeit, L.; Whalen, K.; Nußholz, J. A review and evaluation of circular business model innovation tools. Sustainability 2019, 11, 2210. [CrossRef]

80. Finnveden, G.; Moberg, Å. Environmental systems analysis tools—An overview. J. Clean. Prod. 2005, 13, 1165-1173. [CrossRef]

81. Kaddoura, M.; Kambanou, M.L.; Tillman, A.-M.; Sakao, T. Is prolonging the lifetime of passive durable products a low-hanging fruit of a circular economy? A multiple case study. Sustainability 2019, 11, 4819. [CrossRef]

82. Martínez-Blanco, J.; Lehmann, A.; Muñoz, P.; Antón, A.; Traverso, M.; Rieradevall, J.; Finkbeiner, M. Application challenges for the social Life Cycle Assessment of fertilizers within life cycle sustainability assessment. J. Clean. Prod. 2014, 69, 34-48. [CrossRef]

83. Ishizaka, A.; Labib, A. Analytic hierarchy process and expert choice: Benefits and limitations. OR Insight 2009, 22, 201-220. [CrossRef]

84. Munshi, J. A method for constructing likert scales. SSRN Electron. J. 2014. [CrossRef]

85. Nemoto, T.; Beglar, D. Developing likert-scale questionnaires. In Proceedings of the JALT Conference Proceedings, Tokyo, Japan, 25-28 October 2014; pp. 1-8.

86. Kjaer, L.L.; Pigosso, D.C.A.; Niero, M.; Bech, N.M.; McAloone, T.C. Product/Service-Systems for a Circular Economy: The Route to Decoupling Economic Growth from Resource Consumption? J. Ind. Ecol. 2019, 23, 22-35. [CrossRef]

87. Matschewsky, J. Unintended circularity?-Assessing a product-service system for its potential contribution to a circular economy. Sustainability 2019, 11, 2725. [CrossRef] 